\title{
Deed of Service Assignment from Hermopolis Inv. No. SR 3746 August 166 BCE Measurements 103 X $29.5 \mathrm{~cm}$ Hermopolis
}

\author{
Magdy A. I. Aly \\ Mansoura University
}

\section{INTRODUCTION}

This very long papyrus that close to be a small roll rather than just a papyrus (where its width is one meter and $3 \mathrm{~cm}$ by $29.5 \mathrm{~cm}$ in height). It is kept in Cairo Museum under S.R number 3746 and it has been brought to the museum on November $24^{\text {th }}$ of the year 1962. This small roll consists of 5 Kolleses which are vary in width. The papyrus has a gradual brown color from light brown at the left to dark brown at the right side according to the color of the Kollemata. Apart of some minor vertical breaks at right side probably as a result of a fold, it is in a very good condition and of a good quality. The surface is a fine smooth and it has two modern labels have been glued at the first Demotic column located at first kollema and underneath the Greek text in the third kollema. The papyrus has sliced at the four sides rather than torn, mostly in the antiquity. The left margin as wide as $14.7 \mathrm{~cm}$, top margin $8.6 \mathrm{~cm}$, bottom margin is $6.9 \mathrm{~cm}$, while right margin is the largest $24.8 \mathrm{~cm}$. It seems that the papyrus has been folded four vertical times that caused minor damages, especially between the two Demotic columns and at the right side before the edge. It is not clear that the discoloration of the last four Kollemata is due to their quality or they have been exposed to other factors caused that changing. 


\section{Deed of Service Assignment from Hermopolis}

This bilingual document has preserved two texts: The Demotic ${ }^{1}$ text is written in two columns. First column consists of eleven complete lines, and the second column consists of nine complete lines. The width of first column is: $20.4 \mathrm{~cm}$, while the width of second column is as big as $71.1 \mathrm{~cm}$. The width of Intercolumniation is ca. $8.6 \mathrm{~cm}$. There is no explanation concerning the existence of two columns of the Demotic text instead of one ordinary text. While it preserved three complete lines of the Greek text, certainly without a stichometry. The Greek text has been written just below the second Demotic column and started from the same beginning point as well. Although the space between the Demotic text and the Greek text from the beginning point and until the middle of both texts is larger than the space between them at the second part, yet it is due to the last line of Demotic text starts from the beginning of the column. That might reflects the Chirographic skills of the Greek scribe.

The text is written along the fibers on recto in a relatively small sized cursive hand in black ink with a fine pointed nib. The hand is practiced and business with a tendency toward ligatures. The characteristics of the letters, however, show consistency: rho sometimes a long by ended short leg headed left, sometimes with a short leg, beta once drawn with two vertical short strokes connected from bottom, and once drawn with two oblique strokes close and connected at the top and far at the bottom. epsilon is opened and curved with a tongue drawn in a separate stroke connected to succeeded letter while Theta is a short and contracted. Zeta is a typical zshape and omicron is always tiny or even a dot. The chi is drawn with two intersectional strokes and phi is a small horizontal stroke crossed by long vertical stroke from the middle. The omega is either a small or big and dashed.

The interlinear space are even in spite of the length of the two lines. The first line width is ca. $49.5 \mathrm{~cm}$, while second line width is ca. $30.25 \mathrm{~cm}$. The spaces between words are not even yet it is not scriptura continua. There are some abbreviations (e.g. ${ }^{\circ} \operatorname{E} \rho \mu v^{\prime} \pi \mathrm{o}(\lambda \varepsilon i)$ and $\mu \tilde{\eta}(v \alpha)$ ) and a symbol

\footnotetext{
${ }^{1}$ The Demotic text is currently studied by, Dina, a MA student in department of Archaeology, Mansoura University, under the supervision of my colleague Assoc. Prof. Sohier Waheed.
} 


\section{Magdy A. I. Aly}

in line $2 \tau^{2}$ in addition to some monetary symbols (e.g. $\imath \theta, \chi \alpha \lambda \kappa o \tilde{\text {, }}$

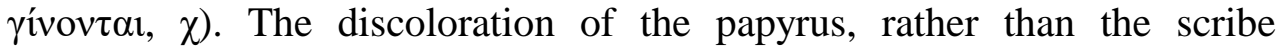
himself, may be the main reason which mars the appearance of the text. The document dates back to 15 August $166 \mathrm{BCE}$, during the $15^{\text {th }}$ year of the reign of Ptolemy the $6^{\text {th }}$, Philometor ${ }^{3}$. As it is cited in line 1 the document belongs to Hermopolis.

The document is a Deed of Service Assignment, and the text shows that Horion son of Seos, with a cognomen ${ }^{4}$ has been assigned to serve in the bank of Hermopolis for five days every month. Thotsytmois the (guard) dog-headed of the temple has received Thotis son of Harpbekis the tax at the rate of $7 \frac{1 / 4}{4}$. The only similar text to this document is what has been published by $\mathrm{CMC}^{5}$. The verso has 16 unpublished Demotic lines.

\section{TRANSCRIPTION}

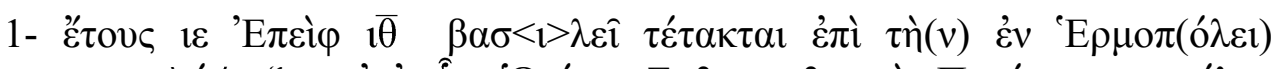

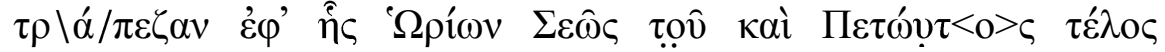

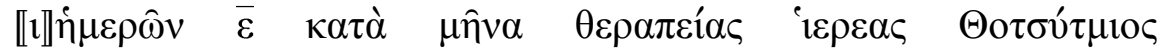

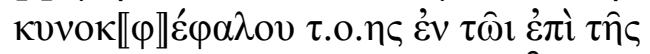

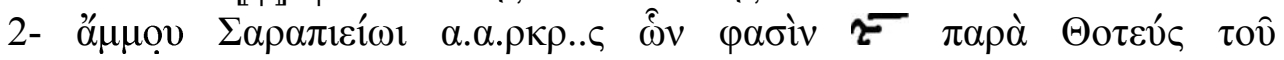

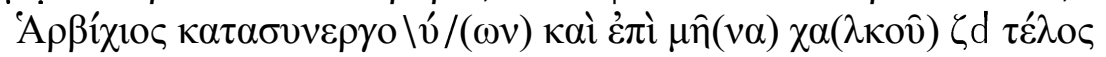

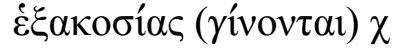

$3-$ $\tau \tau^{\prime} \tau \alpha \kappa \tau \alpha \imath \chi$

\footnotetext{
${ }^{2}$ See note one line 2 in commentary.

${ }^{3}$ The titles of the king in the Demotic text indicate Ptolemy the $6^{\text {th }}$ who reigned from 180 to $145 \mathrm{BCE}$.

${ }^{4}$ See note on line 1 in commentary.

${ }^{5}$ Magdy Aly, Deed of Service Assignment, Hermopolis, 14 January 175

BCE, Center of Mediterranean Civilizations, Volume I, University of

Sohag, 2017, pp. 1 - 10.
} 


\section{Deed of Service Assignment from Hermopolis}

\section{CORRECTION}

Line 1: $\beta \alpha \sigma \lambda \varepsilon \hat{\imath}$

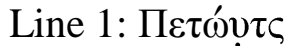

Line 1: in $\mu \varepsilon \rho \hat{\omega} v$

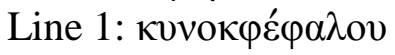

$$
\begin{aligned}
& \rightarrow \quad \beta \alpha \sigma \imath \lambda \varepsilon \hat{\imath}
\end{aligned}
$$

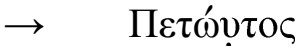

$$
\begin{aligned}
& \rightarrow \quad \dot{\eta} \mu \varepsilon \rho \hat{\omega} \nu
\end{aligned}
$$

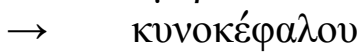

\section{TRANSLATION}

In the year 15, 19 of Epeiph, Horion son of Seos who is also called Petous has been assigned for a service as a tax to the king into the bank at Hermopolis in which the service is for the 5 days every month. Thotsytmis the (guard) dog-headed of the temple who stand with the feet together on the sand of the Serapeum ... the word which ... from Thoteus son of Harpbekis and $71 / 4$ copper per month the tax six hundred total 600 [2 $2^{\text {nd }}$ Hand] he has paid 600

\section{COMMENTARY}

Although it seems there is a semi identicalness of the formulae of S.R. 3744 and S.R. 3746 as well as the short period of time between them "i.e. eight years and five months" that might give an indication of a possibility of one scribe has written both of the two texts, though there are some explicit differences between them represented in:

1- The shape of letters and the way of forming them indicate clearly that the hand that wrote S.R. 3744 is not the same wrote S.R. 3746. For example, the initial epsilon of the beginning of हैंovৎ is an elliptical with attached tongue in this document, and it is rather semi curved with unattached horizontal stroke in S.R. 3744. Also all the letters that have descender have foot in S.R. 3744 (e.g. iota, rho, phi, ...), while they do not have foot in this document. In spite of the orthographic and grammatical peculiarities for both documents are similar, there are many calligraphic characteristics shows more experience in S.R. 3744 rather than S.R. 3746. 


\section{Magdy A. I. Aly}

2- The difference between the formula of the two texts is essentially represented in the following: The title in S.R. 3744 is addressed to the

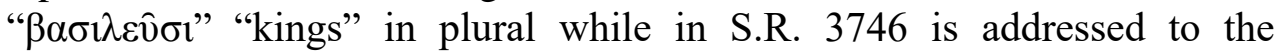
" $\beta \alpha \sigma i \lambda \varepsilon \hat{\imath} "$ "king" in singular (See note in line 1).

3- The monthly service in S.R. 3744 (100) is two and half days, while in 3746 (600) five days.

4- The total amount of tax in S.R. 3744 (100) is smaller than S.R. 3746 (600).

Line 1: "̌兀ovৎ $1 \varepsilon$ 'E $\pi \varepsilon i \varphi ~ 1 \bar{\theta}$ : Although the shape of the epsilon in the year number looks like theta, yet it is five rather than nine because the scribe has a complete oval theta. As it has been mentioned in "Deed of Service Assignment, Hermopolis, 14 January 175 BCE, C M C, 2017, Volume I, University of Sohag, p. 1, there is no indication in the text to a particular king, yet the unpublished Demotic text includes the name and titles of Ptolemy VI. Since the Greek text is the signature of the main Demotic text; the scribe did not need to re-mention the ruler again. But if it would be written it would be expected a regal formula as: " $\beta \alpha \sigma i \lambda \varepsilon \hat{\imath}$

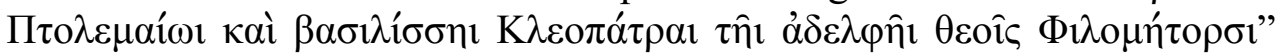
as in: p.amh 2 33, Petition to the King and Queen, Soknopaiu Nesos (Arsinoites), 157 BCE, p.amh 2 34c, Fragments of Petitions, Soknopaiu Nesos (Arsinoites), 157 BCE, p.erasm 1 1, Enteuxis, Oxyrhyncha (Arsinoites), 148 BCE - 147 BCE, sb 8 9681, Enteuxis, Apollonopolis, 175 BCE, upz 1 6, Eingabe gegen Amosis und Genossen, Memphis, 163 BCE, upz 1 9, Ptolemaios' Sorgen um Psichis, Memphis, 161 BCE - 160 BCE, upz 1 10, Ptolemaios' Sorgen um Psichis, Memphis, 160 BCE, upz 1 15, Beschwerde gegen die Militärbehörde, Memphis, 156 BCE, upz 1 16, Beschwerde gegen die Militärbehörde, Memphis, 156 BCE, upz 1 19, Klageschrift gegen Nephoris (späteres Konzept), Memphis, 163 BCE, upz 1 41, Zweite ENTEY $\Xi I \Sigma$ an die Könige, Memphis, 161 BCE - 160 BCE and upz 142 , Eine ENTEY $\Xi I \Sigma$ an die Könige, Memphis, 162 BCE. 


\section{Deed of Service Assignment from Hermopolis}

$\beta \alpha \sigma<1>\lambda \varepsilon \hat{i}$ : The scribe forgot to write the iota, in spite of lifting a space between sigma and lambda.

$\tau \varepsilon ́ \tau \alpha \kappa \tau \alpha \mathrm{l}:$ the verb is usually appears abbreviated after the epsilon $\tau \dot{\varepsilon}(\tau \alpha \kappa \tau \alpha \imath)$ or sometimes after the alpha $\tau \dot{\varepsilon} \tau \alpha(\kappa \tau \alpha \imath)$. Only 85 times the complete form has been written during the Ptolemaic period among 540 attestations.

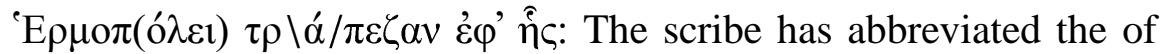
the city by writing subscribed omicron. It is the second time the bank of Hermopolis appears in the documents during the Ptolemaic period. While

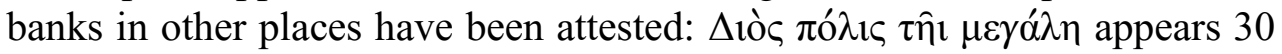

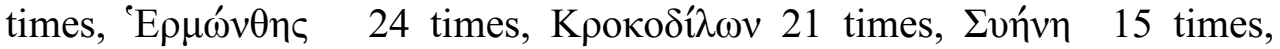

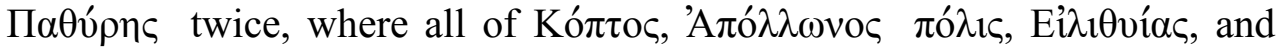
$\Lambda \alpha ́ \tau \omega \vee \pi o ́ \lambda \varepsilon \imath$ only appears only once.

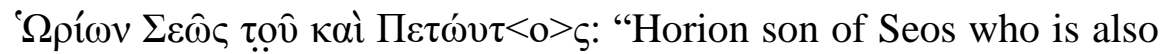
called Petous" ' $\Omega$ pí $\omega v$, or "Hwryzn" in ancient Egyptian language, the Greek derivation of the Egyptian god Horos. His patronymic name $\Sigma \varepsilon \hat{\omega} \varsigma$

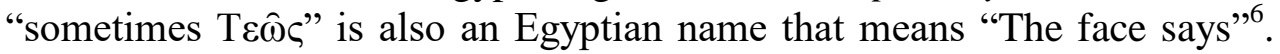
This person has a name and descriptive name "epithet" (Horos with the expressional face).

The conjunction kaí is legible and clear as it is written in line 2, but the problematical reading being before it where it is hard to read the article

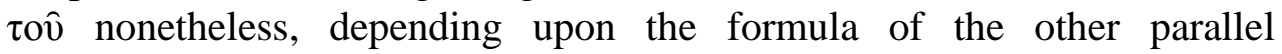
document, it is expected to find an alias afterwards.

$\llbracket 1 \rrbracket \dot{\eta} \mu \varepsilon \rho \omega \hat{v}:$ An orthographic iotacism fault from the scribe where the word is meant to be $\dot{\eta} \mu \varepsilon \rho \hat{\omega} v$, yet he started to write it with iota then he realized it should be written with eta. However, the iota does not seem to be corrected or erased, but rather he left it and wrote the eta afterwards.

\footnotetext{
${ }^{6}$ Demotisches Namenbuch p. 1368-1369 (male \& female); J. Quaegebeur, OLP 4 (1973)
} 


\section{Magdy A. I. Aly}

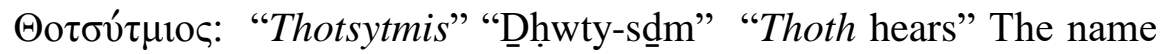
of the guard of the Sarapieion reflects a religious indication to the god Thoth, god of wisdom who was also often depicted as a man with the head of an ibis or a dog-faced baboon ${ }^{7}$. Is it a coincidence that the guard wears a mask represents a dog or jackal and in the same time his name indicates the name of the god that also sometimes depicted with a dog-faced baboon?! However, the chief shrine of the god Thoth was in Hermopolis, to which this document belongs.

The name is cited 6 times in Ptolemaic and 6 times in Roman periods. The Ptolemaic documents among them this person might be mentioned are dated as follows: one in 232 BCE "sb 12 10860, Greek household record (kat' ethnos), Arsinoites", two in $3^{\text {rd }}$ century BCE "p.count 19, Greek household record, Arsinoites (?) and p.meyer 34, Privatbrief, Trikomia? (Arsinoites)", one in first courter of second century BCE "p.tebt 3.2 1015, Accounts of Sitologi, Tebtynis (Arsinoites)", one in $1^{\text {st }}$ half of first century BCE "p.rain.cent 50, Petizione a Apollonius, $\Sigma$ ГГГЕNН $\Sigma$ e stratego, Delta" and one in 99-98 BCE "p.ryl 2 72, Accounts of Sitologi, Arsinoites". None of them mention the same person, and the closest date to this document is: p.tebt 3.2 1015, Tebtynis (Arsinoites), 200 BCE - 176 BCE, Account of Rents (?), yet it can't be the same person because the person in our document is a guard and in p. tebt 3.21015 is a farmer. The stem of the name indicates to an Egyptian origin. It worthy to mention that the name of the guard that in the other document parallels to

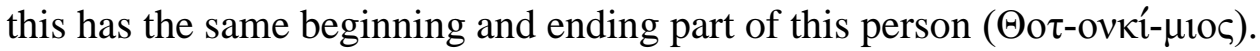

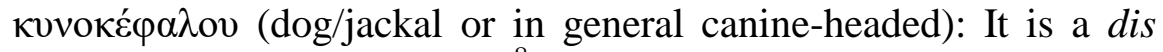
legomenon appears in the documents ${ }^{8}$. Apart from wearing a dog or jackal mask depicts the god Anubis, there is a lack of information about the exact responsibilities of the guard of the temple "Cynocephalus".

${ }^{7}$ Budge, E. A. Wallis. The Gods of the Egyptians Volume 1. New York: Dover Publications, 1969, p. 401

${ }^{8}$ The first appearance is in: Deed of Service Assignment, Hermopolis, 14 January 175 BCE, Center of Mediterranean Civilizations, 2017, Volume I, University of Sohag. 


\section{Deed of Service Assignment from Hermopolis}

น.o.nc: The reading is not certain and according to the other parallel it is expected to find a word such i $\varepsilon \rho 0 \hat{v}$ in this position of the text.

Line 2: ُ Serapeum" $\Sigma \alpha \rho \alpha \pi t \varepsilon i ́ \omega t$ it is in dative case and it should be in genitive (See: p.ryl 2 153, Will of a Hermopolite, Hermopolis, 169 CE and sb 89792 , Strafanzeige $(\pi \rho \circ \sigma \alpha ́ \gamma \gamma \varepsilon \lambda \mu \alpha)$ wegen eines Raubüberfalls, Hermopolis, 162 $\mathrm{BCE})$.

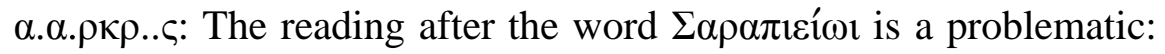
the alpha is clear then the following letter is not certain, then an alpha, then a ligatured letter with rho, the a clear kappa and another rho then another two uncertain letters then finally sigma.

$\hat{\omega} v$ pariv $\widetilde{\tau}$ : The symbol after $\varphi \alpha \sigma i v$ is not clear and there is no a specific word is expected in this place.

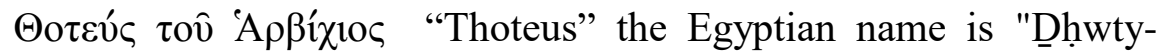
iw"and it means "Thoth has come", "Harpbekis" the Egyptian name is "Hrp3-byk" and it means "Horos the falcon". As a person this is the first time

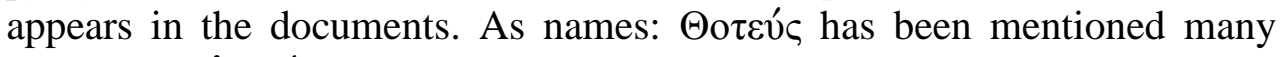
times while A $\rho \beta$ í $\chi 10 \varsigma$ mentioned 20 times 13 in Ptolemaic ear. Thoteus son of Harpbekis is the tax payer.

$\kappa \alpha \tau \alpha \sigma v v \varepsilon \rho \gamma o \backslash v$ / $(\omega v)$ "who stand with the feet together" The scribe has been abbreviated only the ending of word (pres part act nom sg) since it's recognizable. The only attestation for this word is being in bgu 61256 , Gesuch eines Makedonen um Entbindung von der Lampadarchie, Philadelphia (Arsinoites), 147 BCE - 136 BCE.

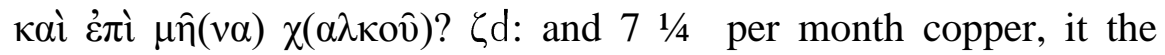
monthly payment of the tax. If the restoration of the month in genitive (i.e. $\mu \eta(v o ̀ c)$, it would be expected to see a name of the month afterwards, but it

${ }^{9}$ See: (Demotisches Namenbuch, p. 802) 


\section{Magdy A. I. Aly}

is not, so the restoration in accusative is logic. The abbreviation and the numbers are clear and legible.

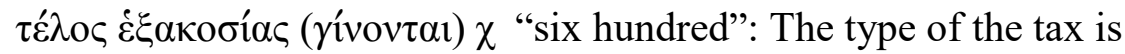
not clear.

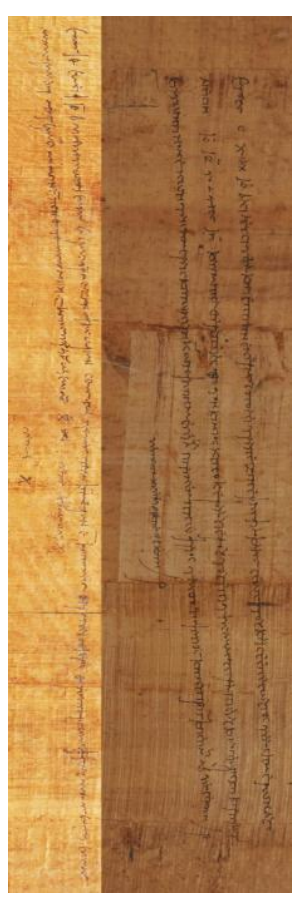

S.R. 3744, 3746

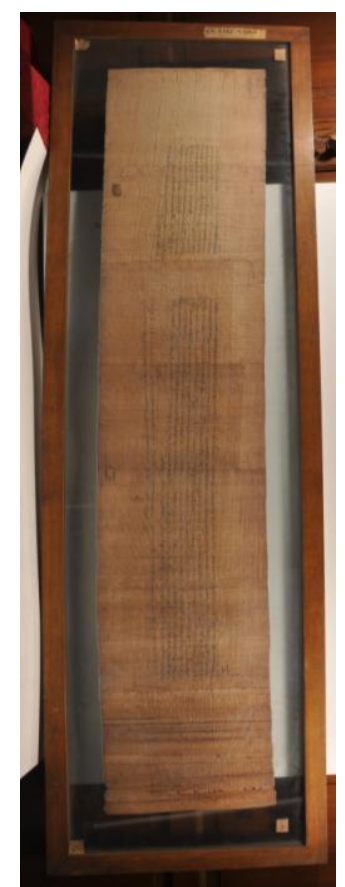

S.R. 3746

Deed of Service Assignment from Hermopolis 